\title{
Dinâmica demográfica da população indígena em áreas urbanas: o caso da cidade de Altamira, Pará*
}

\author{
Alessandra Traldi Simoni ${ }^{\star \star}$ \\ Ricardo de Sampaio Dagnino***
}

\begin{abstract}
Este artigo aborda as populações indígenas no município de Altamira, Estado do Pará, com ênfase em sua presença nas áreas urbanas e, principalmente, na sede municipal. 0 objetivo é compreender os movimentos e dinâmicas destas populações com relação aos dados produzidos sobre/por elas. Para tanto, utilizaram-se informações de campo, dos Censos Demográficos de 2000 e 2010, do Instituto Brasileiro de Geografia e Estatística, e aquelas provenientes de levantamentos visando a identificação de indígenas na cidade para atender à construção da Usina Hidrelétrica de Belo Monte. Procurou-se captar os processos pelos quais a população indígena passou e passa, com destaque para as ameaças provocadas pela usina e por forças políticas que têm colocado esta população em risco. Os resultados apontam para uma presença crescente no meio urbano, principalmente de populações das etnias Juruna, Kuruaya e Xipaya que pareciam ter diminuído significativamente, mas passaram por um processo de recuperação demográfica na cidade associado a um movimento político de articulação em torno de sua identidade étnica a partir dos anos 1990.
\end{abstract}

Palavras-chave: População indígena. Cidade. Amazônia. Altamira.

\footnotetext{
* Os autores agradecem aos pareceristas e ao Comitê Editorial da Rebep pelas valorosas contribuições para o aprimoramento deste trabalho.

** Centro de Pesquisa em Etnologia Indígena, Instituto de Filosofia e Ciências Humanas da Universidade Estadual de Campinas (Unicamp), Campinas-SP, Brasil (lele.traldi@gmail.com).

${ }^{* \star *}$ Universidade Estadual de Campinas (Unicamp), Campinas-SP, Brasil (ricardosdag@gmail.com).
} 


\section{Introdução}

A presença de indígenas nas cidades brasileiras é uma realidade que necessita ser mais bem pesquisada. Essa população ainda é pouco visibilizada e, por vezes, encontra-se em situações de vulnerabilidade social nas cidades, não contando com apoio específico de atendimento à saúde, educação ou apoio da Fundação Nacional do Índio (Funai), que centra suas atividades principalmente para as Terras Indígenas.

Os últimos três Censos Demográficos têm especial importância no que concerne à presença indígena nas cidades. Entre 1991 e 2000, a população indígena residente em áreas urbanas no Brasil cresceu $440 \%$, enquanto na década seguinte diminuiu em $18 \%$ (IBGE, 2011a; TEIXEIRA; MAINBOURG, 2014). A hipótese apresentada pelo IBGE para tal redução foi a introdução da questão sobre etnia, o que teria inibido a resposta afirmativa da categoria indígena, tal qual nos Censos de 1991 e 2000 (IBGE, 2012a). Entretanto, algumas cidades experimentaram grande aumento do contingente de indígenas (TEIXEIRA; MAINBOURG, 2014), em contraposição ao fenômeno observado em escala nacional.

Este é o caso da cidade de Altamira, no Estado do Pará, que teve uma taxa de crescimento da população indígena bastante elevada entre 2000 e 2010, o que sugere uma especificidade concernente aos indígenas daquele município. Para analisar tal presença indígena, é preciso recorrer a informações históricas sobre a constituição da cidade e a migração dos indígenas para a mesma, o que requer a utilização de outros dados para explicar o que foi observado no último Censo Demográfico. 0 objetivo deste trabalho é, portanto, compreender a dinâmica demográfica da população indígena em Altamira. Apresenta-se uma contextualização histórica da formação da cidade, destacando a relação dos povos indígenas com as frentes de ocupação da região e o estabelecimento destes no território onde a cidade se constituiu. É abordado o processo de urbanização pelo qual esta população passou, utilizando os últimos três Censos Demográficos (1991, 2000 e 2010) paralelamente a outras fontes, como os estudos de impacto visando a implantação da usina hidrelétrica de Belo Monte. Por fim, analisam-se com profundidade os resultados obtidos pelo Censo 2010, amparados por ferramentas de geoprocessamento que auxiliam a compreensão da dinâmica deste caso de crescimento vertiginoso. Assim, busca-se contribuir com um olhar crítico sobre as metodologias utilizadas na produção de dados sobre indígenas em áreas urbanas, analisando e refletindo sobre a qualidade e a confiabilidade dos dados produzidos, bem como a relação existente entre a produção destes dados e as dinâmicas de autoidentificação das populações indígenas.

\section{Breve histórico de constituição da cidade de Altamira}

Neste artigo são tratadas, especificamente, a situação da formação da cidade de Altamira e a relação da população indígena com a mesma, abordando sua história e contexto atual. 0 município de Altamira é o maior do Brasil em extensão territorial, estando 
praticamente todo dentro da bacia do Rio Xingu no Estado do Pará (Figura 1). Neste grande território existem apenas duas áreas consideradas urbanas pelo Instituto Brasileiro de Geografia e Estatística (IBGE): a principal é a cidade de Altamira, que concentra grande parte de toda a população municipal; e a outra é a Vila Castelo dos Sonhos, localizada na porção centro-sul do município, na beira da Rodovia BR-163.

FIGURA 1

Localização da cidade de Altamira, Estado do Pará, e porcentagem da população indígena residente na área urbana - 2010

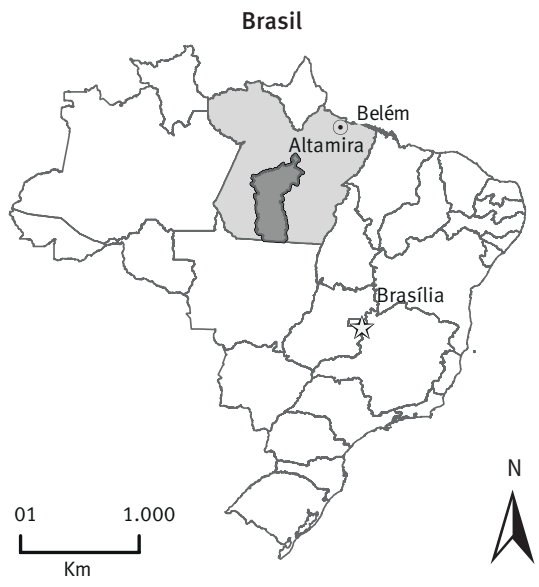

Entorno da sede municipal
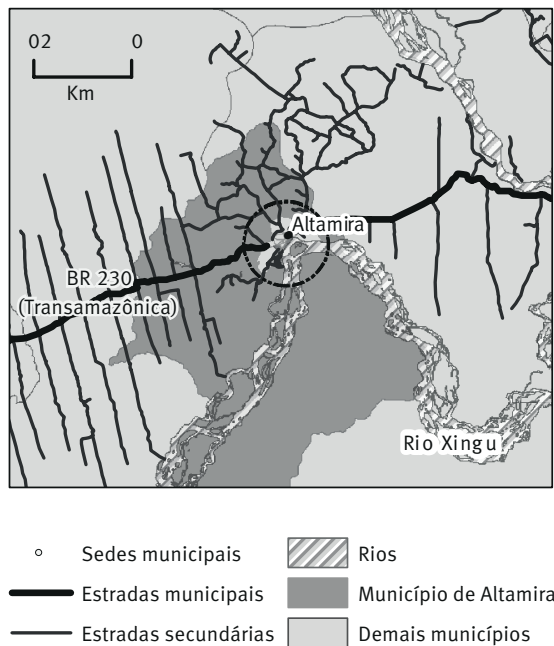

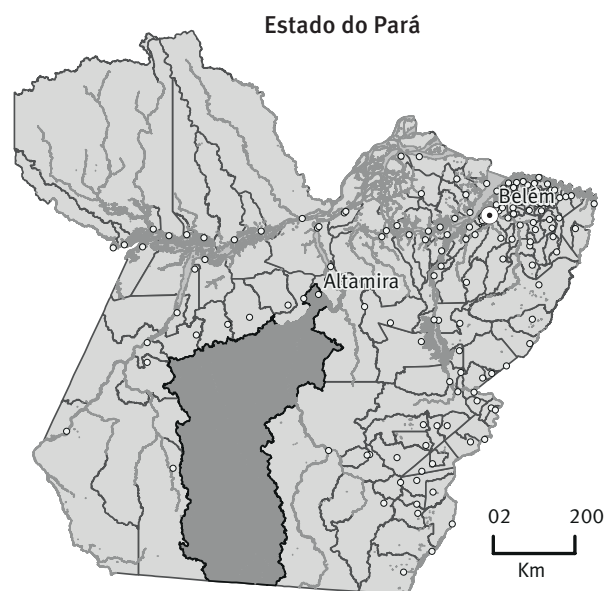

Altamira sede municipal

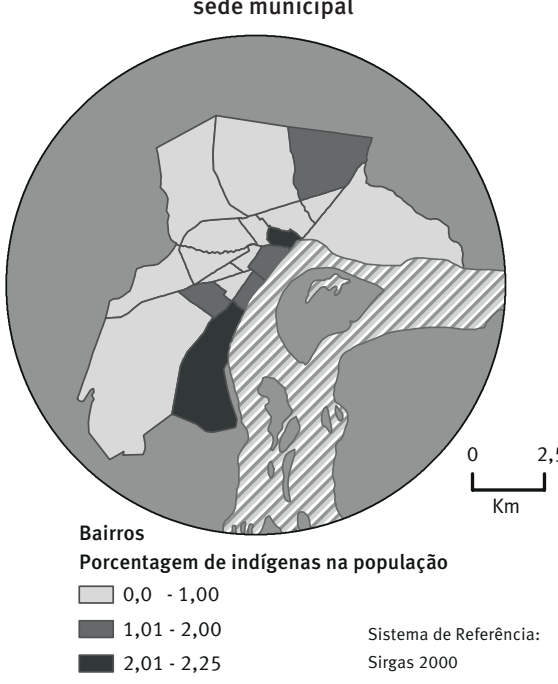

Fonte: IBGE (2011c).

A cidade de Altamira situa-se às margens do Rio Xingu e é a última localidade antes da chamada Volta Grande do Xingu (VGX), grande declive rochoso, de difícil navegação, em que o rio traça seu curso para atingir o Rio Amazonas. Ela é cortada por três igarapés 
que estiveram presentes na história da ocupação do território onde hoje está a cidade de Altamira: Panelas, ao sul; Altamira, no centro; e Ambé, ao norte (Figura 2).

FIGURA 2

Igarapés e bairros da cidade de Altamira - 2010

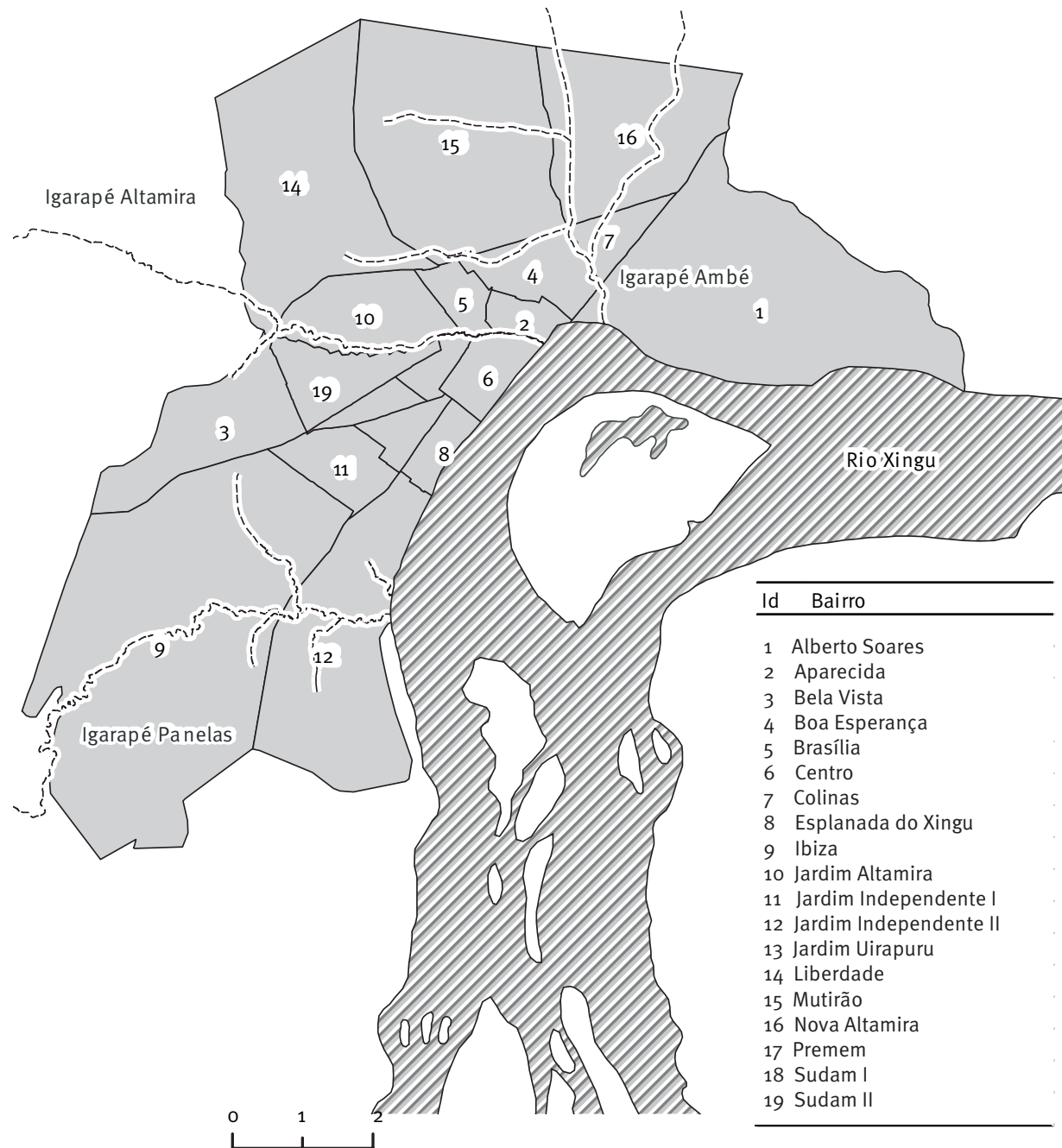

Zio Xingu

-- Igarapés

Sistema de Coordenadas: Sirga 2000

Fonte: IBGE (2011c). Censo Demográfico de 2010 - Malhas digitais dos setores censitários. EIA Belo Monte (LEME, 2009).

Para compreender o processo de ocupação do território e a constituição da cidade, é interessante a divisão em três períodos, cada qual com dinâmicas específicas: aldeamentos missionários (1750-1880); dois períodos durante o ciclo da borracha (1879-1945); e expansão desenvolvimentista (1970 até hoje). Destacam-se, para cada um desses momentos, a participação da população indígena e o seu modo de estabelecimento no espaço urbano. A Tabela 1 
apresenta o total da população no município de Altamira, de 1920 a 2010, apontando o crescimento da cidade, especialmente no período de expansão desenvolvimentista. ${ }^{1}$

Em 1920, Altamira possuía 9.343 habitantes, havendo um importante declínio em 1940 , quando a população diminuiu para 6.428 , o que evidencia o fim do primeiro ciclo da borracha, que durou de 1879 a 1912 (Tabela 1). Posteriormente houve uma pequena recuperação entre 1940 e 1950, período que coincide com o segundo ciclo da borracha. As maiores taxas de crescimento do município, chegando a mais de $350 \%$ entre as décadas de 1970 e 1980, correspondem ao início da implantação de políticas desenvolvimentistas na região, em que a Transamazônica emerge como símbolo de um processo amplo que inclui a criação de agrovilas na região e a atuação de mineradoras e madeireiras. Essa grande mudança, com uma explosão populacional na região, ocorreu entre 2000 e 2010, em virtude da construção da Usina Hidrelétrica de Belo Monte.

TABELA 1

População total, segundo situação de domicílio Município de Altamira - 1920-2010

\begin{tabular}{lrrrrrrrrr}
\hline $\begin{array}{c}\text { Situação de } \\
\text { domicílio }\end{array}$ & 1920 & 1940 & 1950 & 1960 & 1970 & 1980 & 1991 & 2000 & 2010 \\
\hline Urbana & $\ldots$ & 1.813 & 1.939 & 3.118 & 5.905 & 26.905 & 50.145 & 62.285 & 90.068 \\
Rural & $\ldots$ & 4.615 & 5.730 & 8.972 & 9.440 & 19.591 & 22.263 & 15.154 & 14.962 \\
Total & 9.343 & 6.428 & 7.669 & 12.090 & 15.345 & $\mathbf{4 6 . 4 9 6}$ & 72.408 & 77.439 & 105.030 \\
\hline
\end{tabular}

Fonte: IBGE. Censos Demográficos de 1920 a 2010.

É possível que o próximo Censo traga uma dimensão do impacto gerado por essa obra na cidade, mas não do processo que terá ocorrido integralmente no período intercensitário posterior ao Censo 2010, sendo que o impacto dessa obra pode ser considerado análogo àquele experimentado pela cidade na década de 1970, já que a estimativa é de chegada de 100.000 pessoas (MAGALHÃES; HERNANDEZ, 2009), o que dobraria a população da cidade. A presença indígena em Altamira acompanha os ciclos de ocupação do Médio Xingu e do próprio estabelecimento da cidade. Passa-se adiante ao detalhamento destes períodos.

\section{Missão Tavaquara}

0 período das missões no Médio Xingu, ${ }^{2}$ e consequentemente no território que se constituiria como o município de Altamira, se estende de 1750 a 1880 . 0 primeiro marco histórico de colonização da área em que se formou a cidade de Altamira é a missão Tavaquara, formada pelo padre jesuíta Roque Hundertpfund, que em 1750 reuniu, próximo ao igarapé Panelas, indígenas dos povos Arara, Juruna, Kuruaya e Xipaya. Esse aldeamento missionário passou a ser um local reconhecido e de referência para estas populações indígenas não apenas naquele período, especificamente para os Juruna que ali permanecem, mas também como marcador

\footnotetext{
${ }^{1}$ Note-se que, para os Censos de 1872 e 1890, o município não existia e em 1920 não existe o levantamento distinguindo população urbana e rural. Ademais o município sofreu desmembramento em 1991.

2 o Médio Xingu é o trecho do rio que se estende ao longo de todo o município de Altamira.
} 
de memória para a população que hoje vive em Altamira. É importante notar que a ocupação missionária não ocorreu de maneira permanente, sendo uma trajetória de idas e vindas (NIMUENDAJÚ, 1948) e que, ao longo de mais de um século, houve várias tentativas de criação de uma missão em diversos períodos e por diferentes missionários, jesuítas e capuchinhos (OLIVEIRA, 1970), todas sem grande sucesso, pois os aldeamentos não conseguiam reter um contingente populacional ou mesmo se manter por muito tempo.

Destaca-se que o processo de ocupação de Altamira foi dificultado pela Volta Grande do Xingu, obstáculo natural que impedia o rápido acesso ao Médio Xingu (NIMUENDAJú, 1948). Este só foi possível quando uma pequena estrada que ligava o baixo curso do rio ao Igarapé Ambé foi aberta. A estrada, que no período das missões era apenas um pequeno caminho, foi terminada em 1891, permitindo definitivamente o abastecimento e escoamento de produção local, com o estabelecimento de circulação permanente entre pessoas e mercadorias, marcando uma nova etapa na ocupação do território.

\section{Ciclo da borracha}

O período conhecido como ciclo da borracha caracteriza-se por um tipo específico de ocupação não apenas do Médio Xingu, mas de toda a Amazônia, baseado na extração do látex para a fabricação de borracha. Este projeto já era visionado e estudado desde pelo menos 1842, quando o naturalista príncipe Adalberto da Prússia realizou uma expedição de dois meses pelo Rio Xingu voltada "para os interesses econômicos ligados à potencialidade da borracha” (CRIPPA, 2011, p. 245).

A exploração do território se dava por parte dos patrões seringalistas com o estabelecimento de barracões nas bocas dos rios, que controlavam o comércio e a produção de borracha e outros bens de consumo que começavam a circular nas áreas de seringais (LIMA; POZZOBON, 2005). A dinâmica social estabeleceu-se por meio da intensa migração e relações econômicas e sociais instituídas justamente em torno destes barracões e nos seringais, o que sugere a existência de um regime demográfico da borracha (VIEIRA JUNIOR; RAMOS, 2011).

Assim, a primeira frente de expansão a atingir a região de Altamira e que culmina no estabelecimento permanente do povoado é o ciclo da borracha, sendo o primeiro ciclo de 1879 até 1912 e o segundo de 1942 a 1945. A população não indígena instalou-se no povoado às margens do Igarapé Ambé, assim como nas áreas de extração da borracha, nos chamados beiradões dos Rios Xingu e Iriri. Os povos Xipaya, Kuruaya e Juruna tiveram grande importância e participação neste ciclo econômico, pois detinham o conhecimento local de navegação dos rios e dos lugares apropriados para estabelecer os barracões, o que gerou uma relação de troca entre estes e os grupos indígenas já citados, ou como “mediadores de negócios" (SNETHLAGE, 1910, p. 59), ou como trabalhadores nos seringais. É importante ressaltar que este processo foi violento, sendo que muitos indígenas foram escravizados e forçados a deslocamentos para o trabalho nos seringais, como se pode observar no relato de Joaquim Pena, indígena juruna, a Coudreau ([1886]1977, p.76): “Nossa sina é 
a de estarmos sempre em fuga. Antigamente, a gente fugia dos índios bravos; agora, dos civilizados, nossos queridos protetores".

Além disso, as áreas de produção de borracha, especificamente no Rio Iriri, afluente do Rio Xingu, principal local de habitação dos indígenas Xipaya (beira do rio) e Kuruaya (centro da mata), sofriam com conflitos intensos com o povo Kayapó, migrando em direção à área em fuga da expansão da fronteira realizada na região Centro-Oeste do Brasil.

Assim, é neste período que se estabelece uma ampla área de circulação entre os locais de extração e produção da borracha e a cidade de Altamira, onde a produção era negociada e comercializada. Formou-se, desse modo, uma espécie de corredor de trânsito de pessoas e mercadorias ao longo dos Rios Xingu e Iriri e a cidade.

Nesse contexto, adensaram-se as relações entre indígenas e não indígenas, com casamentos interétnicos, tendo grande importância aqueles realizados com os chamados "soldados da borracha", nordestinos enviados pelo governo brasileiro para trabalhar nos seringais e povoar a Amazônia.

O ciclo da borracha encerrou-se em 1945, quando essa atividade entrou em declínio definitivo. Apesar disso, não houve um esvaziamento da região e nem da cidade de Altamira, já que novas atividades foram vislumbradas com a descoberta de garimpos ${ }^{3}$ no Médio Xingu (UMBUZEIRO, 1999). As populações envolvidas na produção da borracha passaram a buscar na cidade de Altamira melhores condições de vida e ali se estabeleceram. 0 local privilegiado de ocupação indígena, notadamente das populações Xipaya e Kuruaya, foi às margens do Igarapé Panelas, vindo a ser denominado "aldeinha” (PATRÍCIO, 2000).

Neste período, a cidade de Altamira cresceu a partir da estrada do Igarapé Ambé, alcançando e incorporando o local da antiga aldeia-missão, no Igarapé Panelas, onde viviam muitos indígenas. Esta região se tornou o Bairro São Sebastião, hoje bairros Independente I e II e Recreio (EIA, 2009 - Mapa IV. 1.2). Dessa maneira é interessante notar como, durante o ciclo da borracha, a população indígena migrou para a cidade, mas escolheu habitar especificamente a "aldeinha", que, por sua vez, foi incorporada ao centro urbano que cresceu a partir do Igarapé Ambé. A população indígena que se estabeleceu na cidade sofreu o impacto das profundas alterações que ocorreram no período seguinte.

\section{Expansão desenvolvimentista}

Altamira teve sua dinâmica radicalmente alterada, neste período, com dois projetos: a construção da Transamazônica, em 1970, e a construção de usinas hidrelétricas no Rio Xingu, idealizada em final da década de 1970, culminando com a construção da Usina Hidrelétrica de Belo Monte, a partir de 2011. Ambos são projetos desenvolvimentistas do período da ditadura que visavam um tipo de relação do Norte com o restante do país, seguindo a lógica de ocupação por meio de uso de recursos naturais, desconsiderando as especificidades locais.

\footnotetext{
${ }^{3}$ A atividade de garimpo tem notada importância na Volta Grande do Xingu e na Área Indígena Curuá, posteriormente Terra Indígena Kuruaya.
} 
Nesse contexto, as grandes empresas de extração de recursos são as madeireiras, mineradoras e hidrelétricas, que fornecem energia para as primeiras, enquanto as rodovias são previstas como obras para escoar a produção. Ainda que a BR-230 (Rodovia Transamazônica) tenha começado as obras de asfaltamento nos anos 2000, as alterações na cidade e Médio Xingu foram brutais, com intensa imigração, redistribuição espacial da população e reorganização espacial. A cidade de Altamira, antes voltada para as atividades econômicas desenvolvidas ao longo dos rios, passou a ter uma importante ligação com a estrada, resultando em uma cidade bicéfala, em que parte se volta para o rio e parte para a estrada.

As populações indígenas que viviam na cidade foram impactadas durante o crescimento da cidade, pois, com a especulação imobiliária, muitos foram expulsos de suas residências e forçados a habitarem bairros mais afastados, preferencialmente às margens dos Igarapés Altamira e Ambé, para além do Panelas, normalmente em áreas de palafita, sem regularização de terrenos, com riscos à saúde por falta de saneamento básico e sujeitas às cheias (ELETRONORTE, 1988; LEME, 2009).

Finalmente, em 2011, com o início da construção da Usina Hidrelétrica de Belo Monte (UHE Belo Monte), na Volta Grande do Xingu, que, quando concluída, será a terceira maior hidrelétrica do mundo, a cidade teve novamente sua dinâmica associada à intensa imigração. A população indígena moradora de Altamira foi mais uma vez diretamente impactada, pois as áreas em que residiam, às margens dos três igarapés que cruzam a cidade, serão permanentemente alagadas pela formação de um dos lagos da barragem. Por não estar em uma Terra Indígena, essa população na cidade pode ser “reassentada”, o que significa sua remoção e a demolição de suas casas, podendo, como compensação, acessar uma carta de crédito ou ter uma nova casa em um dos cinco Reassentamentos Urbanos Coletivos (RUC) construídos pela empresa responsável pela construção da UHE Belo Monte.

\section{Processos de invisibilização e visibilização indígena na cidade de Altamira}

Com base no breve histórico apresentado sobre a formação de Altamira e da presença indígena no contexto urbano, pode-se perceber dois movimentos em relação à organização da cidade em torno da categoria indígena: de invisibilização e visibilização.

Do início dos anos 1880 até 1970, sobretudo durante os dois ciclos da borracha, a população indígena passou por um violento processo de dispersão territorial e aparente desvinculação de sua identidade indígena enquanto grupo. Essa narrativa está presente na bibliografia que trata desta população, em que as categorias descritivas se sobrepunham, acabando por demonstrar esta visão da não-indianidade, índio-manso, índio-civilizado e finalmente não-índio. Assim, os grupos Arara da Volta Grande do Xingu, Juruna, Kuruaya e Xipaya foram considerados extintos no Médio Xingu e em Altamira (MALCHER, 1964), no entanto, chama-se atenção para o fato de que eles estavam e sempre estiveram ali.

É apenas a partir de 1988, no âmbito dos estudos para a viabilização do aproveitamento hidrelétrico do Rio Xingu, que esta população “reaparece”. Tais estudos se concentraram em 
mapear e analisar a população indígena residente na cidade de Altamira, na Volta Grande do Xingu e beiradões, conforme será mostrado adiante.

Já no final dos anos 1990, a própria população indígena da cidade de Altamira passou a se organizar, apoiada pelo Conselho Indigenista Missionário. A organização se deu prioritariamente em torno de associações. Esse processo iniciou-se em 1998, com o Movimento dos Índios Moradores de Altamira, coordenado por Elza Xipaya, e em 2001 foi fundada a Associação de Índios Moradores de Altamira (Aima), com o objetivo de fortalecer a organização dos “índios urbanos" e "afirmar sua identidade étnica” (MAGALHÃES, 2008, p. 66). Novas associações surgiram na cidade e, decorrente deste movimento, houve inclusive, em 2000, uma solicitação de Terra Indígena na cidade de Altamira (PATRíCIO, 2003). É nesse contexto de organização política da população que ocorre uma produção de levantamentos autônomos da população indígena residente em Altamira.

Em 2009, quando foi realizado novamente um grande levantamento da população indígena, no contexto dos Estudos de Impacto Ambiental (EIA) da UHE Belo Monte, mais indígenas se identificaram como tal. A metodologia deste levantamento será tratada no item seguinte, mas é importante ressaltar que este é um momento em que houve uma possibilidade de acesso a políticas destinadas às populações indígenas, em oposição ao período anterior de discriminação estrutural (DEL POPOLO; RIBOTTA, 2011). Foi em virtude dos estudos de diagnóstico que parte desta população tornou-se visível novamente, sendo um momento crucial na história destes grupos. Reafirma-se aqui que se trata de um contexto e não uma arbitrariedade destas populações ao se identificarem como indígenas (BARTOLOMÉ, 2006).

Destaca-se que o tema da (re)constituição étnica de grupos indígenas tem sido um importante debate na antropologia brasileira, havendo diversas linhas teóricas que buscam analisar a questão de maneira a abarcar as complexidades do fenômeno (PANTOJA; COSTA; ALMEIDA, 2011). No entanto, escolheu-se aqui abordar o tema acompanhando as fontes de dados disponíveis, a partir de 1988, para a população indígena que vive na cidade de Altamira, concentrando-se especificamente naquelas em que este grupo passa por algum tipo de recenseamento ou contagem. Acredita-se que, por meio desta escolha metodológica, que já foi utilizada por Crespo (2014), seja possível realizar uma crítica voltada à produção de dados e suas relações com os processos de ressignificação ou (re)constituição étnica pelos quais os povos indígenas passam, foco do presente trabalho. Discutem-se a seguir estas fontes, buscando destacar seus contextos de produção e analisar suas potencialidades e limitações.

\section{Dados: potencialidades e limitações}

A análise demográfica de populações que vivem na Região Norte do Brasil, não apenas as indígenas, apresenta dificuldades quanto à qualidade dos dados e cobertura das pesquisas e registros vitais. Além disso, é preciso levar em conta que se trata aqui do 
estudo de populações indígenas. De pequeno volume populacional, elas trazem desafios metodológicos, já que os métodos utilizados na demografia estão centrados e foram desenvolvidos para a análise de grandes populações.

Os dados sobre populações indígenas no Brasil, de maneira geral, quando existem, têm menor qualidade. No país, apenas populações indígenas que fazem parte de algum programa, como o Projeto Xingu, realizado pela Universidade Federal de São Paulo (Unifesp), contam com uma série de dados confiáveis coletados anualmente. A situação dos povos do Parque Indígena do Xingu é, portanto, uma exceção entre os povos indígenas no Brasil.

A população indígena no Médio Xingu como um todo não possui uma série de dados histórica e de qualidade (PAGLIARO; AZEVEDO; SANTOS, 2005). Para além dessas questões, as populações aqui abordadas, de maior história de contato e que hoje passam por processos de reconhecimento, carregam em si especificidades quanto aos dados, já que por certo período não foram reconhecidas enquanto indígenas. Dessa forma, a população indígena residente na cidade de Altamira foi considerada extinta e apenas recentemente “reapareceu” nos dados censitários e para o Estado brasileiro (SIMONI, 2013).

Os dados disponíveis para esta população se encontram inicialmente no Censo 1991, primeiro censo em que a categoria indígena foi investigada em âmbito nacional, tendo sua captação mantida e melhorada nos censos subsequentes, conforme explica-se a seguir.

A partir do Censo de 1991, o Instituto Brasileiro de Geografia e Estatística (IBGE), acompanhando os movimentos mais amplos de respeito e direito à diversidade étnica, que tiveram início na década de 1970, incorporou a categoria indígena no quesito raça ou cor, que passou a ter também um caráter étnico. Nos Censos Demográficos de 1991 e 2000, a categoria indígena foi incluída na pesquisa da amostra ${ }^{4}$ (IBGE, 2005), ou seja, não foi coletada para todos os domicílios. Em 1991, foram recenseados indígenas em missões religiosas, postos indígenas da Fundação Nacional do Índio (Funai) e em outras áreas não especificadas, ficando de fora "os aborígenes que vivem em tribos, arredias ao contato, conservando seus hábitos primitivos de existência” (IBGE, 1990, p. 10). Em 2000, a cobertura do recenseamento foi maior e melhor, ${ }^{5}$ abrangendo todas as Terras Indígenas, assim como áreas urbanas e rurais (PAGLIARO; AZEVEDO; SANTOS, 2005). A inclusão da categoria indígena nestes dois censos foi um primeiro e importante movimento em direção à visibilidade desta população, sendo um dos passos necessários para a efetivação dos direitos conquistados e estabelecidos na Constituição Federal de 1988. Mesmo havendo tal inclusão, não se conseguiu avançar em direção ao estabelecimento da diversidade dos povos indígenas, pois a referência poderia ser a de um vínculo à categoria como “índio

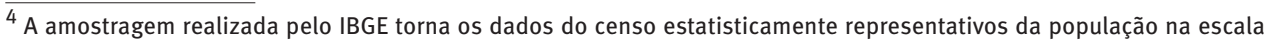
dos municípios, dos estados e do país. No entanto, a amostragem não foi planejada para populações de pequeno número e, dessa forma, não garante representatividade de segmentos sociodemográficos e econômicos específicos. Para uma explicação detalhada do processo de amostragem utilizado nos censos, ver IBGE (2011a).

${ }^{5}$ No Censo 1991, foram comprovadas irregularidades atribuídas a processos fraudulentos e distorções dolosamente introduzidas nos dados de Altamira e de outros municípios do Pará (IBGE, 1994, p. 15-17). Ressalta-se que, para além desta questão, não se utiliza nas análises este censo, pois houve um desmembramento da cidade de Altamira, em que parte foi incorporada ao município de Vitória do Xingu, o que pode levar a conclusões erradas sobre a população pesquisada.
} 
genérico" (PAGLIARO; AZEVEDO; SANTOS, 2005; IBGE, 2005), que se relacionava com uma ancestralidade indígena, em que não era possível entender mais profundamente quais usos eram feitos na opção por responder ao quesito.

O Censo Demográfico de 2010 apresenta um grande avanço na produção de dados sobre as populações indígenas no Brasil. 0 quesito raça ou cor passou a figurar no questionário do universo, abrangendo toda a população brasileira. Além disso, outro importante fator de aprimoramento das informações foi a inclusão de diversas perguntas referentes à maior caracterização da população indígena no país. Ainda no questionário básico (respondido por toda a população brasileira), foram incluídas questões sobre etnia ou povo ao qual o indivíduo pertence e quanto à língua indígena falada no domicílio, com possibilidade para até duas línguas diferentes além da portuguesa (IBGE, 2010; PEREIRA, 2012). Essa é, portanto, a primeira pesquisa a levantar e divulgar dados quanto à diversidade étnica e linguística dos povos indígenas no Brasil. Outro avanço importante foi a inclusão de uma pergunta de verificação somente para as Terras Indígenas, em que, caso o recenseado respondesse não ser indígena na questão sobre raça ou cor, perguntava-se em sequência se o indivíduo se considerava indígena. Essa pergunta é importante, pois consegue captar os indivíduos que porventura respondem à questão raça ou cor segundo a cor da pele e não por sua pertença étnica, sendo esta a variável “condição de indígena”. Entretanto, esta variável não foi utilizada no presente trabalho, por não estar disponível na escala municipal.

Dessa forma, os dados do Censo Demográfico de 2010 (IBGE, 2011a) trazem novas e mais completas informações sobre as populações indígenas no Brasil que ajudam a revelar processos pelos quais estes grupos passaram ao longo dos últimos 30 anos, se considerados os dados desde 1991. No entanto, os dados em si não trazem explicações, mas indicam fenômenos importantes que devem ser mais bem analisados e estudados. Por fim, é interessante observar como os censos disponíveis para análise desta população se encontram no contexto de fortalecimento dos direitos dos povos indígenas e também no processo de rearticulação em torno de sua etnicidade, auxiliando a compreender esta dinâmica demográfica de maneira mais completa. Conforme explicitado na introdução, neste artigo utilizam-se, além dos dados dos Censos Demográficos (1991, 2000 e 2010), as informações obtidas em estudos de viabilidade da Usina Hidrelétrica de Kararaô, em 1988, e da UHE Belo Monte, em 2009, bem como um levantamento autônomo realizado em 2008, pelo Instituto Humanitas, no escopo do projeto de identidade e reconhecimento étnico em Altamira (MAGALHÃES, 2008).

O estudo de viabilidade da UHE Kararaô foi uma pesquisa feita em 1988 pelas seguintes instituições: Centrais Elétricas do Norte do Brasil S/A (ELETRONORTE, 1988), Fundação Nacional do Índio (Funai) e Consórcio Nacional de Engenheiros Consultores S/A (CNEC). 0 objetivo da pesquisa era identificar a população que estaria na área diretamente afetada ${ }^{6}$ pela Usina Hidrelétrica de Kararaô. Duas equipes fizeram o levantamento, sendo que uma,

\footnotetext{
${ }^{6}$ Para o projeto hidrelétrico Kararaô as áreas diretamente afetadas eram: cidade de Altamira, beiradão dos Rios Xingu e Iriri, Volta Grande do Xingu e Posto Indígena Bacajá (ELETRONORTE, 1988, p. 7).
} 
formada por dois técnicos da Funai local e se concentrando na cidade de Altamira, "entrevistou e percorreu as residências dos índios habitantes de Altamira de abril a junho de 1988" (ELETRONORTE, 1998, p. 2). Não há indicação da metodologia utilizada para localizar a referida população, mas sim para identificá-la: "A sua formação étnica, os distingue da sociedade não-índia regional, pois veem-se como índios e também são vistos como tal. Este é o critério sociológico que os coloca enquanto índios, numa situação de contato, em que as diferenças culturais não são visíveis” (ELETRONORTE,1988, p. 7). Um entrevistado faz referência a um "cadastramento" dos indígenas moradores da cidade de Altamira que a Funai estaria realizando (ELETRONORTE, 1988, p. 231), o que indica como o levantamento foi percebido pela população indígena.

Os resultados são apresentados em dois volumes. No primeiro há uma síntese analítica e no segundo são descritas integralmente as respostas de cada domicílio (Casa 01 a $32^{7}$ ) organizadas em dez questões abertas. A pessoa de referência do questionário era 0 indivíduo indígena responsável pelo domicílio. As questões eram: localização geográfica; membros da família além do chefe (com informação de etnia, relação com chefe e idade); histórico da vida do chefe da família; situação socioeconômica; situação fundiária; características da habitação; outros aspectos; relação com a sociedade local; relação com o poder institucional; e aspirações.

Já o levantamento do Instituto Humanitas e os Estudos de Impacto Ambiental da UHE Belo Monte trazem informações sistematizadas por relatórios e estudos feitos com participação da população indígena na execução da pesquisa, seja como entrevistadores, seja como fontes prioritárias de acesso aos núcleos de habitação indígena na cidade e às margens dos Rios Xingu e Iriri.

O tomo que versa sobre os indígenas citadinos e ribeirinhos da Volta Grande do Xingu (VGX), que compõe os Estudos de Impacto Ambiental (EIA) de Belo Monte (LEME, 2009), constitui outro grupo de informações utilizadas.

A metodologia para levantar dados sobre a população indígena foi a da técnica bola de neve (CORNISIER; SERPA, 2010), na qual se recorre a informantes para a localização de outros indivíduos, ampliando cada vez mais o escopo da pesquisa, na busca de atingir a totalidade de recenseamento dos indivíduos pesquisados segundo alguma característica específica. No caso dos estudos de Belo Monte, a característica procurada era a de ser indígena. Assim, foi a partir de informações da população indígena que se mapeou a presença indígena em Altamira, incluindo a realização de genealogia de cada família. Percebe-se que a metodologia não apenas incluía a participação de indígenas, mas também se refletia na concepção do que é ser indígena, pois, a partir do momento em que a população indígena oferece os dados sobre ela, passa a ser incorporada à pesquisa uma concepção propriamente indígena sobre pertença a determinado grupo étnico. Além disso, as entrevistas foram realizadas também por indígenas da região, majoritariamente Xipaya (LEME, 2009).

\footnotetext{
$\overline{7}$ As informações da "Casa" 29 não foram incluídas no relatório, volume 2.
} 
Portanto, esta última fonte de informações tem a participação indígena em dois momentos da produção de dados: na concepção (pelo pressuposto do método utilizado) e na execução, o que leva a observar os dados contidos nos estudos sob a ótica da participação indígena, tornando este tipo de levantamento único, ainda que se esteja ciente das limitações representadas pela maneira como os dados são apresentados nos relatórios finais ${ }^{8}$ e pela circunstância em que a pesquisa foi produzida, no âmbito de um estudo para viabilidade de uma obra que ocasionará deslocamentos compulsórios de parte da população.

Deve-se ressaltar que tais estudos tinham como intenção fornecer um diagnóstico dos impactos relativos à construção da usina, favorecendo assim uma pesquisa nas áreas que serão alagadas com o barramento do Rio Xingu. Portanto, estes dados devem ser incorporados com ressalvas, como representativos de parte de um processo.

\section{Resultados e discussão}

Para a apresentação dos resultados, primeiramente serão abordados os dados censitários para depois realizar uma leitura das informações dos estudos de viabilidade e impacto de projetos de aproveitamento hidrelétrico do Rio Xingu e daquelas contidas no relatório do Instituto Humanitas.

$\mathrm{Na}$ análise dos microdados da amostra dos últimos Censos Demográficos (IBGE, 2000, 2010), observa-se que a população no município de Altamira aumentou de 77.439 para 99.075 habitantes, entre 2000 e 2010 (Tabela 2), com uma taxa de crescimento geométrico de $2,49 \%$ ao ano, mais elevada do que aquelas registradas para o Brasil, a Região Norte e o Estado do Pará (Tabela 3). Nesse período, a população urbana cresceu 3,05\% a.a., passando de 62 mil para 84 mil pessoas, enquanto a rural diminuiu, resultando no aumento de $80 \%$ para $85 \%$ dos habitantes em áreas urbanas. Assim, o município de Altamira atingiu, em 2010, um grau de urbanização bastante elevado, superior àqueles observados para 0 conjunto do país (84,4\%), a Região Norte (73,5\%) e o Estado do Pará $(68,5 \%)$.

Uma fração do crescimento da população urbana no município de Altamira deve-se ao fato de que, em 2010, a população residente na Vila Castelo dos Sonhos, antes considerada pelo IBGE população rural, passou a ser definida oficialmente como população urbana (DAGNINO, 2014). Assim, em 2010, a população urbana do município foi contabilizada em 84.092 pessoas, sendo 6.898 na Vila Castelo dos Sonhos e 77.194 na sede municipal, a cidade de Altamira. Dessa forma, percebe-se que a população municipal está bastante concentrada na sede municipal (cidade de Altamira) onde residem $78 \%$ da população do município e quase $92 \%$ da sua população urbana.

\footnotetext{
${ }^{8}$ Os dados populacionais não foram apresentados no EIA de forma clara e objetiva. As tabelas existentes já contêm análises, o que dificulta a leitura do que representaria cada dado.
} 
TABELA 2

População residente total e autodeclarada como indígena, segundo situação de domicílio Brasil, Região Norte, Estado do Pará, Município de Altamira e Cidade de Altamira - 2000-2010

\begin{tabular}{|c|c|c|c|c|c|c|c|}
\hline População & $\begin{array}{c}\text { Situação de } \\
\text { domicílio }\end{array}$ & Ano & Brasil & Norte & Pará & $\begin{array}{c}\text { Altamira } \\
\text { (Mun.) }\end{array}$ & $\begin{array}{l}\text { Altamira } \\
\text { (Cidade) }\end{array}$ \\
\hline \multirow{6}{*}{$\begin{array}{l}\text { População } \\
\text { total }\end{array}$} & \multirow{2}{*}{ Urbana } & 2000 & 137.925 .238 & 9.027 .976 & 4.122 .101 & 62.285 & 62.285 \\
\hline & & 2010 & 160.934 .649 & 11.669 .066 & 5.193 .636 & 84.092 & 77.194 \\
\hline & \multirow{2}{*}{ Rural } & 2000 & 31.947 .618 & 3.883 .194 & 2.073 .864 & 15.154 & - \\
\hline & & 2010 & 29.821 .150 & 4.195 .388 & 2.387 .415 & 14.983 & - \\
\hline & \multirow{2}{*}{ Total } & 2000 & 169.872 .856 & 12.911 .170 & 6.195 .965 & 77.439 & 62.285 \\
\hline & & 2010 & 190.755.799 & 15.864 .454 & 7.581 .051 & 99.075 & 77.194 \\
\hline \multirow{6}{*}{$\begin{array}{l}\text { População } \\
\text { indígena }\end{array}$} & \multirow{2}{*}{ Urbana } & 2000 & 383.298 & 46.304 & 11.718 & 125 & 125 \\
\hline & & 2010 & 321.748 & 61.082 & 8.747 & 877 & 868 \\
\hline & \multirow{2}{*}{ Rural } & 2000 & 350.829 & 167.140 & 25.962 & 1.165 & - \\
\hline & & 2010 & 499.753 & 244.070 & 29.386 & 3.168 & - \\
\hline & \multirow{2}{*}{ Total } & 2000 & 734.127 & 213.443 & 37.681 & 1.289 & 125 \\
\hline & & 2010 & 821.501 & 305.152 & 38.134 & 4.045 & 868 \\
\hline
\end{tabular}

Fonte: IBGE (2002, 2012b). Censos Demográficos 2000 e 2010: microdados da amostra.

TABELA 3

Taxas de crescimento geométrico anual da população residente total e autodeclarada como indígena, segundo situação de domicílio

Brasil, Região Norte, Estado do Pará, Município de Altamira e Cidade de Altamira - 2000-2010

Em \% a.a.

\begin{tabular}{llccccc}
\hline População & $\begin{array}{l}\text { Situação de } \\
\text { domicílio }\end{array}$ & Brasil & Norte & Pará & $\begin{array}{c}\text { Altamira } \\
\text { (Mun.) }\end{array}$ & $\begin{array}{c}\text { Altamira } \\
\text { (Cidade) }\end{array}$ \\
\hline \multirow{3}{*}{ Total } & Urbana & 1,55 & 2,60 & 2,34 & 3,05 & 2,17 \\
& Rural & $-0,69$ & 0,78 & 1,42 & $-0,11$ & - \\
\hline \multirow{2}{*}{ Indígena } & Total & 1,17 & 2,08 & 2,04 & 2,49 & 2,17 \\
\hline
\end{tabular}

Fonte: IBGE (2002, 2012b). Censos Demográficos 2000 e 2010: microdados da amostra.

Em relação à população autodeclarada indígena, verificou-se um crescimento bastante elevado em Altamira, tanto em termos relativos como absolutos. Em 2000 residiam no município 1.289 indígenas, que representavam 1,66\% da população municipal, quantidade que triplicou em 2010, chegando a 4.045 índios e aumentando sua participação para 4\% da população total. Nas áreas urbanas do município, a população indígena passou de 125 para 877 pessoas, entre 2000 e 2010, ampliando sua participação na população total de $0,20 \%$ para $1 \%$ (Tabela 4 ).

A população indígena em situação urbana, em 2010, concentrava-se na cidade de Altamira, onde residiam 868 autodeclarados indígenas. As áreas rurais permanecem sendo o local de residência da maior parte da população indígena de Altamira, mas isso está mudando. Assim, se em 2000 apenas 10\% dos índios residiam em áreas urbanas, em 2010 este percentual saltou para $21,7 \%$, sendo que do total da população indígena 
em área urbana, 99\% residem na sede municipal (cidade de Altamira) e apenas 1\% na Vila de Castelo dos Sonhos.

TABELA 4

Participação da população indígena na população total, segundo situação de domicílio Brasil, Região Norte, Pará, Município de Altamira e Cidade de Altamira - 2000-2010

\begin{tabular}{lcccccc}
\hline $\begin{array}{c}\text { Situação de } \\
\text { domicílio }\end{array}$ & Ano & Brasil & Norte & Pará & $\begin{array}{c}\text { Altamira } \\
\text { (Mun.) }\end{array}$ & $\begin{array}{c}\text { Altamira } \\
\text { (Cidade) }\end{array}$ \\
\hline \multirow{2}{*}{ Urbana } & 2000 & 0,28 & 0,51 & 0,28 & 0,20 & 0,20 \\
& 2010 & 0,20 & 0,52 & 0,17 & 1,04 & 1,12 \\
\hline \multirow{2}{*}{ Rural } & 2000 & 1,10 & 4,30 & 1,25 & 7,69 & - \\
& 2010 & 1,68 & 5,82 & 1,23 & 21,14 & 1,66 \\
\hline \multirow{2}{*}{ Total } & 2000 & 0,43 & 1,65 & 0,61 & 4,08 & 1,12 \\
\hline
\end{tabular}

Fonte: IBGE (2002, 2012b). Censos Demográficos 2000 e 2010: microdados da amostra.

Enquanto a população total do município de Altamira registrou crescimento anual de $2,49 \%$ entre 2000 e 2010, a população indígena cresceu 12,12\% a.a. no mesmo período, passando de 1.289 para 4.045 pessoas. Analisando o crescimento segundo a situação de residência, percebe-se que a taxa foi mais elevada nas áreas urbanas (de 125 pessoas para 877 , o que representa uma taxa de $21,5 \%$ a.a.) do que no rural (de 1.165 para 3.168, ou seja, 10,5\% a.a.), embora o volume de população indígena em áreas rurais ainda seja superior (um saldo de 2.291 pessoas no rural, em 2010, contra 1.040, em 2000).

Em relação à distribuição da população por sexo e idade em 2010 (Gráfico 1), apresentada em valores absolutos (com distintas escalas), nota-se que no município de Altamira a pirâmide etária dos indígenas em situação urbana difere da rural. Nas áreas rurais, predominam os homens e mulheres de 0 a 9 anos de idade. Já nas áreas urbanas nota-se um perfil diferente, em que as diferenças por sexo ficam mais claras e os grupos etários mais representativos são aqueles de idades mais avançadas do que no rural. 0 grupo de indígenas com 10 a 19 anos de idade possui o maior peso relativo, em ambos os sexos. Nas áreas urbanas os homens de 40 a 49 anos têm elevada participação na população, proporcionalmente mais relevante do que a das mulheres e a dos homens de outros grupos etários.

Ao se analisar a população indígena por bairro da cidade (Tabela 5), percebe-se que sua distribuição espacial não é aleatória no tecido urbano, destacando-se a presença de indígenas às margens dos igarapés, nos bairros Independente I e II, que correspondem justamente ao antigo local da missão, conhecido como aldeia-missão, anteriormente Bairro São Sebastião (SARAIVA, 2005, p.104). Há também presença nos bairros Centro e Aparecida, próximos ao Igarapé Altamira, ocupação caracterizada principalmente por moradia em palafitas. A dispersão pela cidade ocorreu em virtude da construção da Transamazônica nos anos 1970, quando a população da cidade foi afetada pela pressão imobiliária, bem como pelo aumento populacional em Altamira. Desse modo, muitos indígenas se deslocaram para outros bairros na cidade, havendo uma dispersão populacional. 


\section{GRÁFICO 1}

População indígena, por sexo e idade, segundo situação de domicílio Município de Altamira - 2010

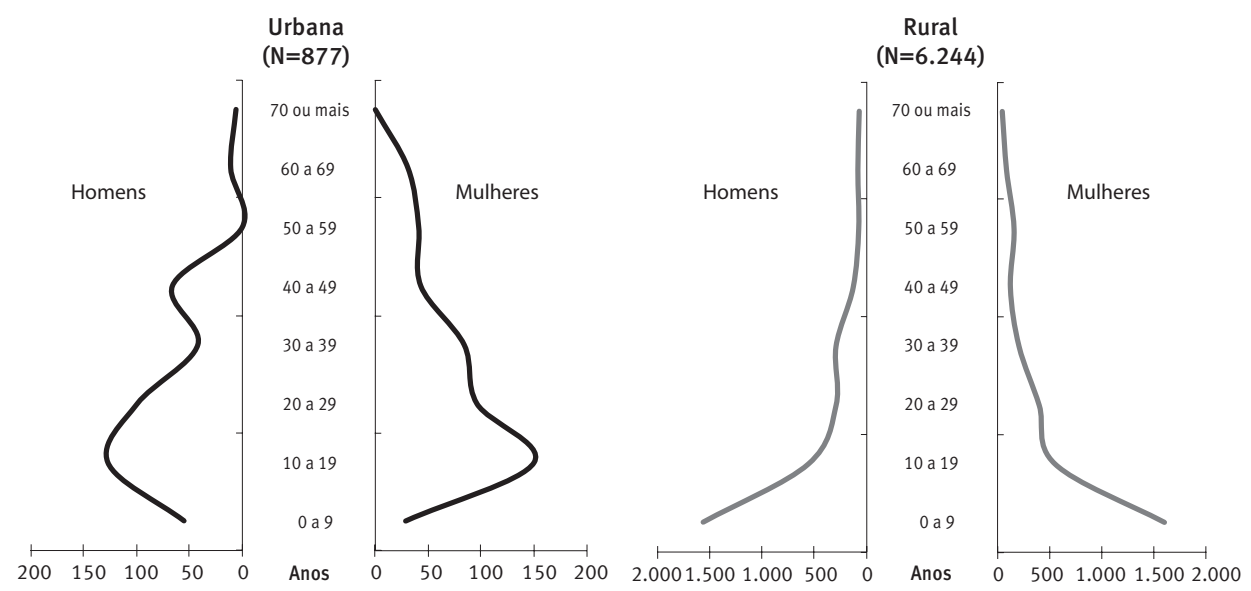

Fonte: IBGE (2012b). Censo Demográfico 2010: microdados da amostra.

TABELA 5

População total e indígena e participação de indígenas na população total, segundo bairros Cidade de Altamira - 2010

\begin{tabular}{|c|c|c|c|}
\hline $\begin{array}{l}\text { Bairros da cidade de } \\
\text { Altamira }\end{array}$ & População total & População indígena & $\begin{array}{c}\text { Participação de } \\
\text { indígenas na } \\
\text { população total (\%) }\end{array}$ \\
\hline Cidade de Altamira & 77.193 & 819 & 1,06 \\
\hline Bairro Centro & 9.746 & 129 & 1,32 \\
\hline Bairro Esplanada do Xingu & 4.635 & 58 & 1,25 \\
\hline Bairro Jardim Uirapuru & 2.435 & 4 & 0,16 \\
\hline Bairro Jardim Independente II & 3.301 & 87 & 2,64 \\
\hline Bairro Brasília & 7.186 & 43 & 0,60 \\
\hline Bairro Liberdade & 2.171 & 18 & 0,83 \\
\hline Bairro Boa Esperança & 10.933 & 140 & 1,28 \\
\hline Bairro Colinas & 3.007 & 8 & 0,27 \\
\hline Bairro Sudam I & 1.553 & 1 & 0,06 \\
\hline Bairro Premem & 2.198 & 4 & 0,18 \\
\hline Bairro Sudam II & 2.855 & 14 & 0,49 \\
\hline Bairro Jardim Independente I & 7.725 & 116 & 1,50 \\
\hline Bairro Ibiza & 1.626 & 12 & 0,74 \\
\hline Bairro Bela Vista & 3.650 & 29 & 0,79 \\
\hline Bairro Mutirão & 6.392 & 33 & 0,52 \\
\hline Bairro Jardim Altamira & 2.878 & 7 & 0,24 \\
\hline Bairro Aparecida & 2.849 & 81 & 2,84 \\
\hline Bairro Alberto Soares & 32 & - & 0,00 \\
\hline Bairro Nova Altamira & 2.021 & 35 & 1,73 \\
\hline
\end{tabular}

Fonte: IBGE (2011b). Censo Demográfico 2010: resultados do universo agregados por setores censitários. 
A partir destes dados, é possível perceber a importância da presença da população indígena na cidade de Altamira, principalmente nos bairros próximos aos Igarapés Ambé, Panelas e Altamira, bem como às margens do Rio Xingu. A relevância está tanto no volume de indígenas quanto na sua participação na população do bairro (Figura 3).

FIGURA 3

População indígena e participação de indígenas na população dos bairros Cidade de Altamira - 2010
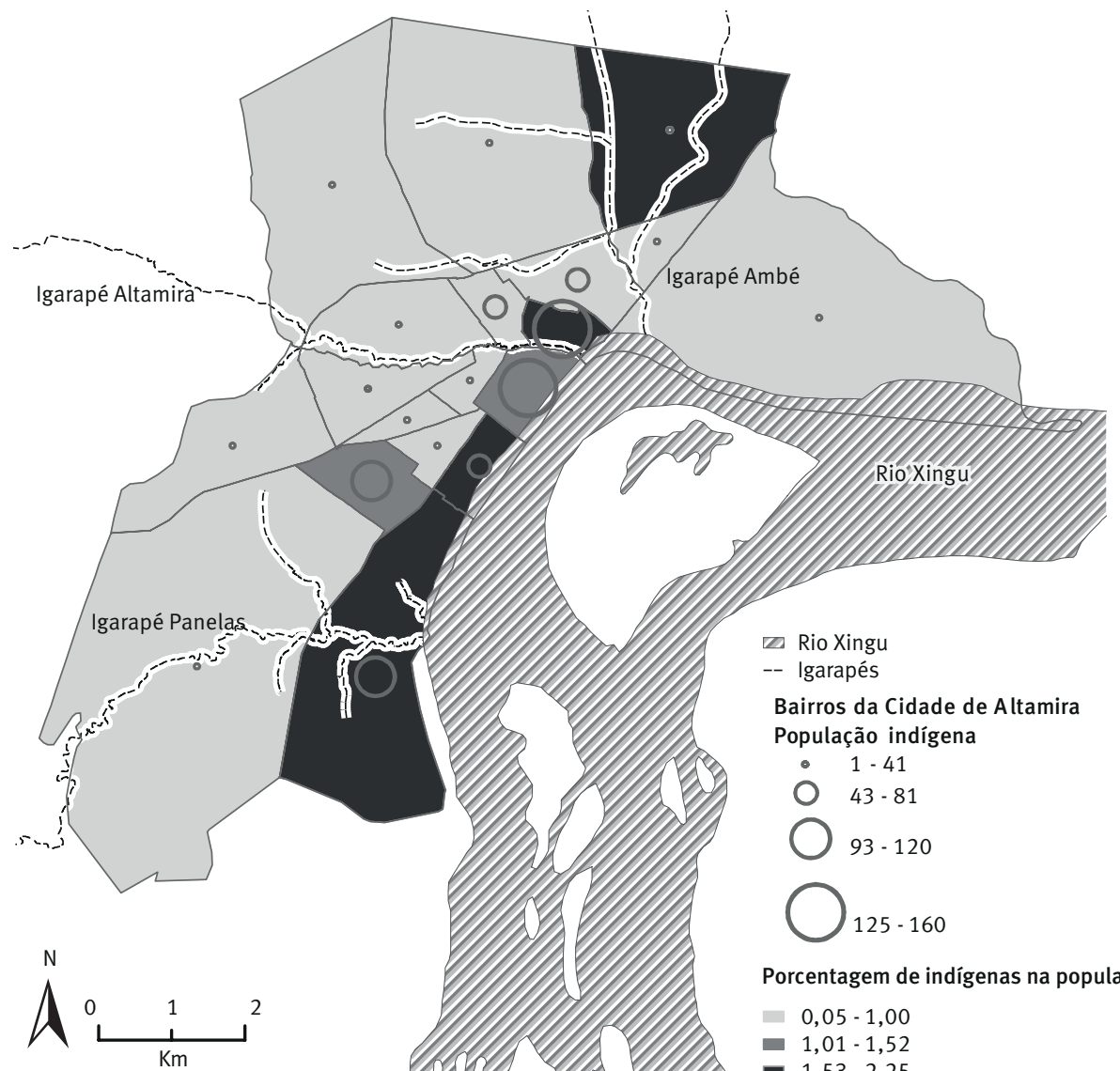

Sistema de Coordenadas: Sirgas 2000

Porcentagem de indígenas na população

$0,05-1,00$

- $1,01-1,52$

= $1,53-2,25$

Fonte: IBGE (2011b, 2011c). Censo Demográfico de 2010: resultado do universo agregados por setores censitários. EIA Belo Monte (LEME, 2009).

Do total de domicílios onde foram aplicados os questionários da amostra do Censo 2010 na cidade de Altamira (IBGE, 2012b), selecionaram-se os 36 que possuíam pelo menos um morador indígena (Tabela 6). Nestes domicílios, foram entrevistadas 157 pessoas (sem expansão da amostra), sendo 83 declaradas indígenas. Ao expandir a amostra pelo peso das pessoas, tem-se que a população de indígenas na cidade de Altamira é de 868 pessoas e os não indígenas que residem em domicílios com indígenas somam 830 pessoas. Assim, nota-se que os domicílios indígenas são formados por um grande 
contingente (1.700 pessoas), entre indígenas e não indígenas. Em 88,9\% desses domicílios, os indígenas estavam na posição de responsáveis $(66,7 \%)$ ou cônjuges (22\%), enquanto nos demais os indígenas eram filho(a) ou sogro(a). Este tipo de análise dos domicílios indígenas pode ser uma importante ferramenta para diminuir a "invisibilidade demográfica e epidemiológica” dessa população, ainda mais quando se leva em conta a diversidade étnica (MARINHO; SANTOS; PEREIRA, 2011).

TABELA 6

Distribuição dos domicílios com indígenas, segundo relação do indígena com o responsável pelo domicílio Cidade de Altamira - 2010

\begin{tabular}{lcc}
\hline Relação do indígena com o responsável & Domicílios & $\%$ \\
\hline Todos residentes são indígenas & 8 & 22,22 \\
Responsável e cônjuge indígenas convivendo com filhos indígenas e não indígenas & 1 & 2,78 \\
Responsável e filhos indígenas convivendo com cônjuge não indígena & 4 & 11,11 \\
Cônjuge com filhos ou enteados indígenas, com responsável não indígena & 4 & 11,11 \\
Somente o responsável é indígena & 11 & 30,56 \\
Somente o cônjuge é indígena & 4 & 11,11 \\
Filho é indígena, mas pais são pardos ou brancos & 2 & 5,56 \\
Somente filho do responsável é indígena & 1 & 2,78 \\
Somente sogro é indígena & 1 & 2,78 \\
\hline Total & 36 & $\mathbf{1 0 0 , 0 0}$ \\
\hline
\end{tabular}

Fonte: IBGE (2012b). Censo Demográfico 2010: microdados da amostra, variável V0502-Relação com responsável pelo domicílio, com valores amostrados (não expandidos).

Deve-se ressaltar que os grupos étnicos Xipaya, Kuruaya e Juruna correspondem a $77,65 \%$ da população indígena da cidade de Altamira (EIA, 2009, p. 79), mas não são os únicos. Existe, ainda, a presença de indígenas que se reconhecem como pertencentes a outras etnias, no entanto, estes não passaram pelo processo aqui apresentado e sua história deve ser analisada de maneira diversa para que se possam compreender as dinâmicas próprias destes indivíduos.

É interessante, portanto, perceber a dinâmica própria da população indígena na cidade de Altamira, em que há uma discrepância entre os dados do Censo e os levantamentos realizados localmente, sendo que os últimos sempre apresentam uma população maior (Tabela 7).

TABELA 7

População indígena e número de famílias pesquisadas, segundo fonte dos dados Cidade de Altamira - 1988-2010

\begin{tabular}{llcc}
\hline \multicolumn{1}{c}{ Ano } & Levantamento/Fonte & População indígena & Número de famílias \\
\hline 1988 & Eletronorte & 242 & 32 \\
1991 & Censo & 211 & - \\
2000 & Censo & 125 & - \\
$2006 / 2007$ & Magalhães (2008, p. 40) & 1.251 & 275 \\
2009 & Leme (2009, p. 80) & 1.625 & 340 \\
2010 & Censo & 868 & - \\
\hline
\end{tabular}

Fonte: IBGE (1991, 2002, 2012b); Eletronorte (1988); Magalhães (2008); Leme (2009). 
Buscando uma chave para compreender como ocorre essa disputa pelo reconhecimento e visibilidade, pode-se ler a produção de dados locais pela dimensão de controle social de quem se percebe e é percebido enquanto indígena, seja Juruna, Kuruaya ou Xipaya. Essa possibilidade existe, mas de maneira mais dispersa quanto à produção de dados estatais, nominalmente dos Censos nacionais, já que a declaração de pertencimento a uma etnia acontece de maneira particular, entre recenseador e recenseado, ainda que existam uma lógica e processo gerais que informem essa declaração. 0 controle social das fontes de dados ocorre pela metodologia utilizada ("bola de neve") e na presença da população indígena enquanto parte do processo de produção de dados, incluída tanto como parte da metodologia quanto no papel de entrevistadores (CORBISIER; SERPA, 2010).

Outro ponto essencial a se tratar é a composição do domicílio e laços de parentesco. Conforme dito anteriormente, a população residente em domicílios com pelo menos um indígena totaliza 1.700 pessoas, segundo o Censo de 2010. Afinal, esta é uma questão crucial a ser levada em conta em contextos em que a população indígena está dispersa e se relaciona com não indígenas. Não seria necessário incorporar nestas situações o domicílio como um todo para analisar a população indígena? Os dados de Altamira sinalizam que essa seria uma postura interessante, diante da proximidade entre o levantamento do EIA Belo Monte, que contabilizou 1.625 pessoas.

Já a divergência entre os dados obtidos dos Censos de 1991 e 2000, em contraposição ao de 2010, é possível ser compreendida com base nos levantamentos locais. Em 1988 a população indígena contabilizava 242 pessoas. A maioria dos indígenas de referência dos domicílios entrevistados havia se estabelecido em Altamira na década de 1940, sendo a maior parte composta por Xipaya e Kuruaya, nascidos nas áreas do Iriri e Curuá. De maneira geral, os entrevistados não sabiam ou não quiseram fornecer detalhes sobre a vida anterior ao estabelecimento na cidade. Neste contexto de fragilização da memória e dos laços étnicos, ocorre a recuperação demográfica dos grupos, especialmente Xipaya e Kuruaya, sendo que dos 32 domicílios entrevistados, em apenas dois há casamento entre indígenas, em todos os outros o casamento é entre indígena e não indígena.

0 relatório do Instituto Humanitas aponta ainda algumas características desta população. Mesmo havendo casamentos entre “indígena e não indígena os filhos são reconhecidos pela etnia, seja do pai ou da mãe. Entre duas etnias há uma escolha de comum acordo entre pai e mãe, havendo casos de ambos" (MAGALHÃES, 2008, p. 41). Mesmo havendo esse reconhecimento e pertença, o relatório aponta ainda que entre jovens de 30 a 35 anos há "quase ausência de memória do passado" (MAGALHÃES, 2008, p. 62), em que se chama a atenção para a dificuldade de transmissão de saberes no contexto urbano de dispersão. Ainda assim, uma característica importante da população indígena que permanece é sua relação com o território. É destacada a "grande mobilidade e relação entre cidade e aldeias, cidade e lotes rurais e cidade e garimpo" (MAGALHÃES, 2008, p. 46). A pertença indígena 
se faz presente também na maneira de ocupação do território do Médio Xingu, caracterizado pela mobilidade iniciada no ciclo da borracha, conforme apontado anteriormente.

Além da recuperação demográfica na cidade, há também o movimento político associado a uma reorganização em torno da etnicidade. Este processo também indica a migração de declaração sobre categoria indígena entre os Censos de 1991, 2000 e 2010.

Destaca-se, por fim, a importância dos levantamentos de 2008 e 2009, em que a população indígena participa e se apropria politicamente da produção de dados sobre a mesma, o que pode também ter contribuído para o aumento da declaração, mesmo com a inclusão da pergunta sobre etnia em 2010.

\section{Conclusão}

Pode-se perceber como, utilizando uma análise da história dos povos indígenas que hoje vivem na cidade de Altamira, é possível compreender com maior exatidão o processo de "urbanização" dos mesmos e como a dinâmica de invisibilização e visibilização impacta na produção de dados sobre os mesmos. Recorrendo a este histórico, pode-se compreender de outra maneira os resultados disponíveis no Censo Demográfico de 2010. Assim, muitas das questões interessantes que surgiram neste último censo, tal como o crescimento da população indígena residente na cidade de Altamira, podem ser respondidas ao se observarem os processos pelos quais passa essa população hoje e suas chaves de interpretação.

Abordaram-se aqui principalmente os processos de migração das populações Juruna, Xipaya e Kuruaya e seu estabelecimento na cidade de Altamira, ainda que seguindo com grande mobilidade entre os beiradões e a cidade.

Apesar de não ser foco do presente artigo, é importante notar que se constatou, por meio das análises das informações dos estudos de viabilidade de Kararaô (ELETRONORTE, 1988) e dos estudos de impacto ambiental de Belo Monte (LEME, 2009), a permanência da violação dos direitos e desrespeitos à população indígena moradora da cidade de Altamira.

A cada momento histórico a população indígena foi expulsa de seu local de residência; primeiramente pelo ciclo da borracha, quando ocorreu a migração forçada para a Altamira. Ainda assim, os grupos se estabeleceram comunitariamente no bairro conhecido como Aldeinha. No entanto, durante a década de 1970, houve uma dispersão por outros bairros, próximos aos igarapés. Agora, em virtude da construção da UHE Belo Monte, a maior parte dos indígenas citadinos sofrerá com a reorganização da dinâmica de ocupação espacial na cidade de Altamira, pois as famílias que vivem próximas aos igarapés serão reassentadas, com cada núcleo familiar com uma casa e dispersão, em cinco novos bairros de Altamira, nos chamados Reassentamentos Urbanos Coletivos (RUC), afastados do centro e distantes do rio.

Buscou-se, com uma análise histórica e com o auxílio de levantamentos locais, mostrar o ganho para a interpretação de dinâmicas demográficas aparentemente inexplicáveis, 
como o crescimento da população indígena residente em Altamira, contrariando a tendência nacional.

\section{Referências}

ABA - Associação Brasileira de Antropologia. Convenção para a grafia dos nomes tribais. Revista de Antropologia, São Paulo, ano 2, n. 2, 1954.

AZEVEDO, M. Demografia dos povos indígenas do Alto Rio Negro. Revista Brasileira de Estudos de População, v. 11, n. 2, p. 235-244, 1994.

. Censos Demográficos e "os índios": dificuldades para reconhecer e contar. In: RICARDO, C. (Org.). Povos indígenas no Brasil - 1996 a 2000. São Paulo: Instituto Socioambiental, 2000. p. 79-83.

. O Censo 2010 e os povos indígenas. In: RICARDO, B.; RICARDO, F. (Ed.). Povos indígenas no Brasil 2006/2010. São Paulo: Instituto Socioambiental, 2011.

BARTOLOMÉ, M. As etnogêneses: velhos atores e novos papéis no cenário cultural e político. Revista Mana, v. 12, p. 39-68, 2006.

CORBISIER, A.; SERPA, P. Índios citadinos de Altamira e famílias indígenas ribeirinhas da Volta Grande do Xingu: aspectos demográficos, socioeconômicos e culturais. In: III ENCUENTRO LATINOAMERICANO CIENCIAS SOCIALES Y REPRESAS, Belém, 30/11 a 03/12 2010. Anais... Belém, 2010;

COUDREAU, H. Viagem ao Xingu. Belo Horizonte: Itatiaia; São Paulo: Edusp, 1977.

CRESPO, C. Memorias de silencios en el marco de reclamos étnico-territoriales. Experiencias de despojo y violencia en la primera mitad del siglo XX en el Parque Nacional Lago Puelo (Patagonia, Argentina). Cuicuilco, v. 21, n. 61, p. 165-187, 2014.

CRIPPA, G. A organização e as políticas do conhecimento ao longo do tempo: desbravando a Amazônia. Revista de Ciência da Informação e Documentação, Ribeirão Preto, v. 2, n. 1, p. 243-246, jan./jul. 2011.

DAGNINO, R. Dinâmica demográfica e indicadores socioeconômicos em escala intramunicipal: municípios de Altamira e São Félix do Xingu, Estado do Pará, entre 2000 e 2010. Tese (Doutorado em Demografia) - Universidade Estadual de Campinas, Instituto de Filosofia e Ciências Humanas, Campinas, 2014.

DEL POPOLO, F.; RIBOTTA, B. Migración de jóvenes indígenas em America Latina. In: DEL POPOLO, F.; CUNHA, E.; RIBOTTA, B.; AZEVEDO, M. (Coord.). Pueblos indígenas y afrodescendientes en América Latina: dinámicas poblacionales diversas y desafíos comunes. Rio de Janeiro: Asociación Latinoamericana de Población, 2011 (Serie Investigaciones, n. 12.). p. 101-125.

ELETRONORTE. Estudos de viabilidade - UHE Kararaô - antropologia indígena. São Paulo, v. I e II, 1988.

IBGE - Instituto Brasileiro de Geografia e Estatística. X recenseamento geral do Brasil - 1990: Censo demográfico: CD 1.09 - Manual do recenseador. Rio de Janeiro: IBGE, 1990.

Censo Demográfico 2000: microdados da amostra. Rio de Janeiro, nov. 2002.

. Censo Demográfico 2010: sinopse do Censo Demográfico 2010. Rio de Janeiro, 2011a.

Base de informações do Censo Demográfico 2010: resultados do universo agregados por setor censitário. Rio de Janeiro, 2011b. 
Censo Demográfico 1991: resultados do universo relativos às características da população e dos domicílios. Número 7 - Pará. Rio de Janeiro, 1994.

2011c.

Censo Demográfico 2010: malhas digitais dos setores censitários. Rio de Janeiro,

Censo Demográfico 2010: características gerais dos indígenas: resultados do universo. Rio de Janeiro, 2012a.

Censo Demográfico 2010: microdados da amostra. Rio de Janeiro, 2012b.

Mapa etno-histórico do Brasil e regiões adjacentes. Adaptado do mapa de Curt Nimuendajú, 1944. Rio de Janeiro, 1981.

Tendências demográficas. Uma análise dos indígenas com base nos resultados da amostra dos Censos Demográficos 1991 e 2000. Rio de Janeiro, 2005.

LEME Engenharia. Estudos de impacto ambiental: aproveitamento hidrelétrico Belo Monte. Volume 35, Estudos etnoecológicos, Tomo 7 - Citadinos e Ribeirinhos da Volta Grande do Xingu. Elaborado por Leme Engenharia para a Eletrobrás e Ministério de Minas e Energia. Maio de 2009.

LIMA, D.; POZZOBON, J. Amazônia socioambiental: sustentabilidade ecológica e diversidade social. Estudos Avançados, São Paulo, v. 19, n. 54, p. 45-76, 2005.

MAGALHÃES, A. C. Identidade e reconhecimento étnico: índios citadinos em Altamira. Belém: Instituto Humanitas, Coleção Índios, 2008.

MAGALHÃES, S.; HERNANDEZ, F. Painel de especialistas: análise crítica do Estudo de Impacto Ambiental do Aproveitamento Hidrelétrico de Belo Monte. Belém, 2009. Disponivel em: 〈http:// www.socioambiental.org/banco_imagens/pdfs/Belo_Monte_Painel_especialistas_ElA.pdf . Acesso em: 10 jun. 2012.

MALCHER, J. M. G. Índios: grau de integração na comunidade nacional, grupo linguístico, localização. Rio de Janeiro: Conselho Nacional de Proteção aos Índios, 1964.

MARINHO, G.; SANTOS, R.; PEREIRA, N. Classificação dos domicílios “indígenas” no Censo Demográfico 2000: subsídios para a análise de condições de saúde. Revista Brasileira de Estudos de População, v. 28, n. 2, p. 449-466, 2011.

NIMUENDAJÚ, C. Tribes of the lower and middle Xingu river. In: STEWARD, J. H. (Ed.). Handbook of South American Indians. Washington: Smithsonian Institute, 1948. v. 3.

OLIVEIRA, A. E. Os índios Juruna do alto Xingu. Dédalo, v. 6, n. 11/12, 1970.

PAGLIARO, H.; AZEVEDO, M.; SANTOS, R. Demografia dos povos indígenas no Brasil: um panorama crítico. In: PAGLIARO, H.; AZEVEDO, M.; SANTOS, R. (Org.). Demografia dos povos indígenas no Brasil. Rio de Janeiro: Fiocruz e Associação Brasileira de Estudos Populacionais, 2005.

PANTOJA, M.; COSTA, E.; ALMEIDA, M. Teoria e prática da etnicidade no Alto Juruá Acreano. Raízes, v. 31, n. 1, p. 118-136, 2011.

PATRÍCIO, M. Índios de verdade? O caso dos Xipaia e Curuaia. Dissertação (Mestrado) Universidade Federal do Pará, Belém, 2000.

. Xipaya. In: ISA - Instituto Socioambiental. Enciclopédia dos povos indígenas no

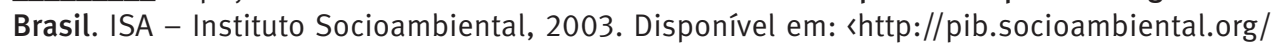
pt/povo/xipayà. Acesso em: 10 maio 2012.

PEREIRA, N. Inovações na pesquisa do indígena do Censo Demográfico 2010 do Brasil e um perfil demográfico dos indígenas residentes na fronteira brasileira. In: V CONGRESSO DA ASSOCIAÇÃO 
LATINOAMERICANA DE POPULAÇÃO. Anais... Montevideo: Alap, 2012. Disponível em: 〈http:// www. alapop.org/2009/index.php?option=com_content\&view=article\&id=887\&ltemid=518 . Acesso em: 10 nov. 2012.

SARAIVA, M. Identidade multifacetada: a reconstrução do "ser indígena” entre os Juruna do médio Xingu. Dissertação (Mestrado) - Universidade Federal do Pará, Belém, 2005.

SIMONI, A. T. Demografia e identidade do povo Xipaya no Médio Rio Xingu, PA. Dissertação (Mestrado em Demografia) - Universidade Estadual de Campinas, Campinas, 2013.

STEINEN, K. V. D. O Brasil Central: expedição em 1884 para a exploração do Rio Xingu. Rio de Janeiro: Companhia Editora Nacional, 1942.

SNETHLAGE, E. A travessia entre o Xingu e o Tapajoz. Boletim do Museu Emilio Goeldi, VII, 1910.

TEIXEIRA, P.; MAINBOURG, E. O que os dados dos censos demográficos do Brasil mostram sobre o crescimento da população indígena nas cidades. In: XIX ENCONTRO NACIONAL DE ESTUDOS POPULACIONAIS. Anais... São Pedro: Abep, 2014.

UMBUZEIRO, U. Altamira e sua história. Altamira: Prefeitura Municipal de Altamira, 1999.

VIEIRA JUNIOR, A.; RAMOS, A. Guia de fontes para história da população na Amazônia 17501800. Belém: Açaí, 2011.

\title{
Sobre os autores
}

Alessandra Traldi Simoni é mestre em Demografia, na área de Demografia e Etnias, pela Universidade Estadual de Campinas - Unicamp e bacharel em Ciências Sociais, com habilitação em Antropologia. Pesquisadora do Centro de Pesquisa em Etnologia Indígena - CPEI/Unicamp e colaboradora de projetos na área de demografia de etnias no Núcleo de Estudos de População "Elza Berquó" - Nepo/Unicamp.

Ricardo de Sampaio Dagnino é pós-doutorando em Análises Demográficas Espaciais na Faculdade de Ciências Aplicadas da Universidade Estadual de Campinas -FCA/Unicamp e bolsista da Fundação de Amparo à Pesquisa do Estado de São Paulo - Fapesp. Pesquisador do Laboratório de Urbanização e Mudanças no Uso e Cobertura da Terra - I-UM/FCA/Unicamp e do Núcleo de Estudos de População “Elza Berquó” - Nepo/Unicamp.

\section{Endereço para correspondência}

\author{
Alessandra Traldi Simoni \\ Rua Prefeito Passos, 215, ap. 131, Vila Itapura \\ 13023-220 - Campinas-SP, Brasil \\ Ricardo de Sampaio Dagnino \\ Rua Ângelo Grigol, 88 \\ 13085-460 - Campinas-SP, Brasil
}




\begin{abstract}
Demographic dynamic of indigenous populations in urban areas: a study case of the city of Altamira, Pará, Brazil

This paper focus on indigenous people in the municipality of Altamira, in the State of Pará, Brazil, emphasizing the presence of indigenous people in urban areas and especially in the city of Altamira. The purpose here is to understand the dynamics and movements of these populations in regard to the data produced about them and the data produced by them. For that, data from fieldwork are used, as well as the demographic censuses data of 2000 and 2010, produced by the Brazilian Institute of Geography and Statistics, and also information from surveys produced because of the construction of the hydroelectric plant of Belo Monte to identify the indigenous people living in the city. The paper intends to capture the processes by which the indigenous population has passed and still passes, highlighting the threats posed by the Belo Monte dam construction and by political forces that have put this population at risk. The results point to a growing presence populations in urban areas, mainly from the Juruna, Kuruaya and Xipaya ethnicities who once seemed to have decreased significantly, but underwent to a demographic recovery process in the city, associated with a political movement pivot around their ethnic identity since the 1990's.
\end{abstract}

Keywords: Indigenous populations. City. Brazilian Amazon. Altamira.

\title{
Resumen
}

Dinámica demográfica de poblaciones indígenas en áreas urbanas: estudio de caso de la ciudad de Altamira, Pará, Brasil

Este artículo enfoca los pueblos indígenas en el municipio de Altamira, estado de Pará, Brasil, destacando la presencia de estos en las zonas urbanas y, especialmente, en la ciudad de Altamira. El objetivo es comprender las dinámicas y movimientos de estas poblaciones en relación a los datos producidos por y sobre ellas. Con este fin, se utilizo datos de campo, los de los censos demográficos de 2000 y 2010, producidos por el Instituto Brasileño de Geografía y Estadística, y informaciones de las encuestas para la identificación de los pueblos indígenas en la ciudad para cumplir con la construcción de la central hidroeléctrica de Belo Monte. Se busco captar los procesos por los cuales la población indígena ha pasado y todavía pasa, destacando las amenazas planteadas por la hidroeléctrica y por las fuerzas políticas que han llevado a esta población en riesgo. Los resultados apuntan a una creciente presencia de esas poblaciones en las áreas urbanas, principalmente de las etnias Juruna, Kuruaya y Xipaya que parecían haber disminuido sobremanera, pero se sometieron a un proceso de recuperación demográfica en la ciudad, asociado con un movimiento político en torno a su identidad étnica a partir de los años 1990.

Palabras clave: Poblaciones indígenas. Ciudades. Amazonía brasileña. Altamira.

Recebido para publicação em 02/12/2015

Recomendado para publicação em 29/07/2016

Aceito para publicação em 08/08/2016 